\title{
The Impact of Creativity Orientation in Achieving Competitive Advantage in Pharmaceutical Companies in Jordan
}

\author{
Dr. Mohammad Izzat Alhalalmeh \\ Associate Prof. - Dept. of Business Administration - Al-Balqa Applied University \\ Princess Alia University College
}

\begin{abstract}
The study aimed to investigate the impact of creativity orientation in achieving competitive advantage. The study used the descriptive and analytical research methods, which were appropriate for the purpose of research. For achieving the study objectives, a questionnaire was designed and distributed. The target population consisted of all managers, head departments and directors. The researcher used a random sample method and designed a questionnaire to collect data from the study sample. The researcher distributed (90) questionnaires and (15) questionnaires dropped due to incomplete answers; therefore, (75) were analyzed. Different statistical methods were used to achieve the objectives of the study. The results showed that there is a statistically significant impact at $(\alpha \leq 0.05)$ level of creativity orientation on competitive advantage in Jordan pharmaceutical companies. The results also concluded that there is a statistically significant Impact at $(\alpha \leq 0.05)$ level of creativity orientation on competitive dimensions (quality, flexibility and responsiveness). The study recommends that pharmaceutical companies should alert all employees with the role of creativity orientation in achieving competitive advantage.

Keywords: Creativity orientation, Competitive advantage, Quality, Flexibility, Responsiveness, Pharmaceutical companies.

DOI: $10.7176 / \mathrm{EJBM} / 12-8-06$

Publication date:March $31^{\text {st }} 2020$

\subsection{Introduction}

Creativity has become an important tool for dealing with new developments, as it has become the key to any competitive advantage, which in its turn is the primary base on which the performance of organizations is based. While it is difficult for business organizations to have competitive edge at all levels and in all cases compared to other competitors, it imposes on it the pursuit of competitive advantages that make it outperform its competitors, and leads it to development and success by relying on resources of an intangible nature, foremost of which is the creative orientation that is a decisive factor in the ability of organizations to achieve competitive advantage, as it is a special tool in the hands of organizations, specifically organizations seek entrepreneurship through the exploitation of the changes as an opportunity to shift and move the product, service, or strategies and policies applicable to what is best to ensure the quality of work at the lowest cost and as soon as possible.
\end{abstract}

\subsection{Study statement}

Due to intensive competition witnessed, it has become difficult for institutions that adopt effective competitive strategies to confront and remain in an environment characterized by complex and rapid changes, which requires these institutions to direct their interests towards building and developing competitive strategies that ensure their continuity and superiority over their competitors, which necessitates great attention to the creative approach. Hence, the problem of the study is concentrated in answering the following question:

- What is the effect of creative orientation on achieving competitive advantage in pharmaceutical companies in the Hashemite Kingdom of Jordan?

\subsection{Research Objectives}

The research aims to identify creativity orientation role in achieving competitive advantages, in addition to the following objectives:

1. To propose a model of how the creativity orientation achieves competitive advantage

2. To write a theoretical framework for the study variables.

3. To provide recommendations for the decision makers.

\subsection{Research significance}

The research importance stems from the importance of the topic it deals with represented by creative orientation. The subject of the study research and its importance come from the following:

1. It helps pharmaceutical companies to activate the creative orientation in a manner that helps these companies to achieve competitive advantage.

2. Increasing Jordanian companies' awareness regarding the benefits of creativity orientation. 


\subsection{Research Hypotheses}

The main hypothesis:-

H0-1 There is no statistical significant impact of creativity orientation at level $(a \leq 0.05)$ on competitive advantage in pharmaceutical companies in Jordan.

This hypothesis is divided into the following sub hypotheses:

H01.1: There is no statistical significant impact of creativity orientation at level $(\alpha \leq 0.05)$ on quality in pharmaceutical companies in Jordan.

H01.2: There is no statistical significant impact of creativity orientation at level $(\alpha \leq 0.05)$ on responsive in pharmaceutical companies in Jordan.

H01.3: There is no statistical significant impact of creativity orientation at level $(\alpha \leq 0.05)$ on flexibility in pharmaceutical companies in Jordan.

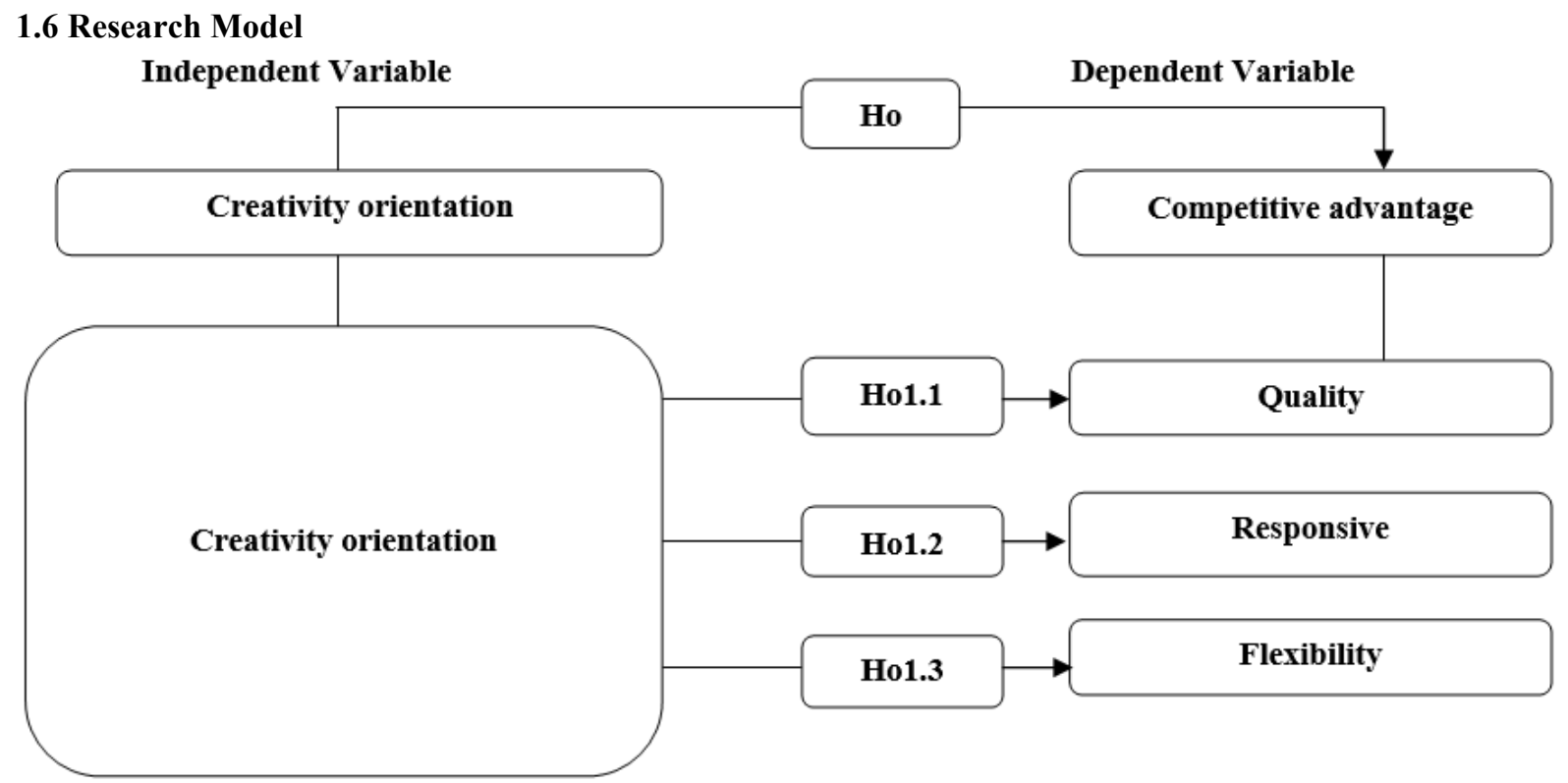

Figure (1-1): The research model

(Developed by the researcher according to previous studies)

\section{Literature Review}

Innovation orientation is a philosophy that promotes openness to new concepts, and reflects a firm's temperament to alter through the adoption and implementation of latest technologies, resources, skills, and administrative systems (Hasani, 2016).Berthon, Hulbert and Pitt (1999) define innovation orientation from the perspective technological excellence: companies that "devote their energy toward inventing and processing superior product" Hamel (2006) described innovation more broadly as "a marked departure from traditional management principles, processes and practices or a departure from customary organizational forms that significantly alters the way the work of management is performed". Innovation offers vital advantages to firms like maintaining or enhancing market share and outperforming competitors (Lisboa, Skarmeas, \& Lages, 2011).

Dobni (2010) indicated that innovation orientation describes how innovative of an organization is and the results suggest that such an orientation provides a context for the implementation of proactive growth-based strategies. Organizations that have high innovation orientations are engaged in value creation strategies such as market segmentation, developing new products and services for new markets, While organizations who have low innovation orientations practice less aggressive and internally focused strategies, .

\section{Theoretical framework}

\subsection{Competitive Advantage}

Sigalas et al. (2013, p 324) defined competitive advantage as "the capability of a firm to create more economic value than the least efficient competitions". Wang, (2014) argued that when accompany has characteristics or attributes that are not owned by its competitors then it has a competitive advantage. Wang, (2014) also argued that competitive advantage is deemed as: performance heart in market competition since competition forms the success or failure core of any company. 


\subsection{Creative Orientation and Competitive advantage}

Askar\&Mortagy (2007) stated that Innovation is a key dimension of competitive advantage due to its ability in finding new opportunities in the external environment, control and quick response to it by achieving certain development or creative work, whether in production field and used technology, or finding new methods for generation more values in institution economic activity. Dobin (2010) found that there is a relationship between creative orientation and competitive strategies.

Alshibly (2015) found that that there is a significant effect of creativity orientation in achieving competitive advantage in Jordan telecom group, Dobin (2010) found that there is a positive relationship between creative orientation and company performance. Hasani (2016) found that there is a significant relationship between firm's orientation toward innovation and competitive strategy; the more firm's orientation toward innovation, the firms uses more Prospector strategy, and their strategies have a more aggressive state. Competitors

\section{Research Methodology}

Descriptive methodology was used in this research. This approach provides statistical data and suitable for descriptive research. The quantitative approach has various advantages, for example, the possibility of its results generalization moreover it prevents any personal bias, because there is no interaction between the researcher and the respondent (Creswell, 2017).

\subsection{Research Instrument}

A self-administrated questionnaire was used as research instrument, the questionnaire was designed in two parts, and the first part part is consistd of questions related to demographic data. The second part included the statements that evaluate the role innovation orientation in competitive advantage.

\subsection{Population and Sampling}

The study target population consisted of all managers, head departments and directors working at Jordanian 15 pharmaceutical companies. The researcher distributed 90 questionnaires, six respondents from each company. However, 90 questionnaires were returned and 15 questionnaires were dropped due to incomplete answers. Therefore, 75 questionnaires were analyzed and the response rate was $83.3 \%$.

\subsection{Research Validity}

The questionnaire was subject to validation by number of university staff and their comments and amendments were taken in consideration.

\subsection{Research Reliability}

The study used Cronbach alpha to test the consistency of the results produced by the scale. According to this test, the overall reliability level was equal to (0.968) which are considered as an acceptable level of reliability Table (.1) shows values of Cronbach's alpha for each variable of the questionnaire and the entire questionnaire.

Table (1): Instrument reliability

\begin{tabular}{|l|c|}
\hline \multicolumn{1}{|c|}{ Variable } & Cronbach Alpha \\
\hline Creativity Orientation & 0.960 \\
\hline Quality & 0.964 \\
\hline Flexibility & 0.877 \\
\hline Responsiveness & 0.950 \\
\hline Total Instrument & $\mathbf{0 . 9 6 8}$ \\
\hline
\end{tabular}

\section{Data Analysis}

The first part outlines the general and demographic information about the respondents and data analysis of the study to find percentages, standard deviation and mean for the study variables. The second part includes a statistical analysis performed on the study of the data to test and find the statistical significance of the study hypotheses. 


\subsection{Descriptive Analysis}

Table (2): Sample distribution according to Demographic information

\begin{tabular}{|c|c|c|c|}
\hline Variables & Options & Frequency & Percentage $\%$ \\
\hline \multirow[t]{2}{*}{ Gender } & Male & 41 & 54.7 \\
\hline & Female & 34 & 45.3 \\
\hline \multirow[t]{3}{*}{ Age } & Less than 30 & 4 & 5.3 \\
\hline & 30 to less than 40 & 34 & 45.3 \\
\hline & 40 to less than 50 & 37 & 49.3 \\
\hline \multirow[t]{3}{*}{ Education level } & $\mathrm{BSC}$ & 41 & 54.7 \\
\hline & MSC & 25 & 33.3 \\
\hline & PHD & 9 & 12.0 \\
\hline \multirow[t]{6}{*}{ Position } & Manager & 27 & 36.0 \\
\hline & Deputy manger & 16 & 21.3 \\
\hline & Head section & 25 & 33.3 \\
\hline & Marketing manger & 3 & 4.0 \\
\hline & Puplic Relation manager & 4 & 5.3 \\
\hline & Directors & 0 & 0.0 \\
\hline \multirow[t]{4}{*}{ Experience } & Less than 5 years & 11 & 14.7 \\
\hline & 5 to less than 10 years & 20 & 26.7 \\
\hline & 10 to less than 15 & 23 & 30.7 \\
\hline & $15+$ & 21 & 28.0 \\
\hline
\end{tabular}

Table (2) indicated that $54.7 \%$ of the sample is males and $45.3 \%$ are females, As for age $5 . .3 \%$ of the sample are less than 30 years old, while $45.3 \%$ of the sample their age ranged from 30 to less than 40 years, $49.3 \%$ of the sample their age ranged between 40 to less than 50 years old .With respect to education level, $54.7 \%$ of the total sample have BSC, while $33.3 \%$ of the sample have MSC and $12 \%$ of the sample have PHD. As for position $36 \%$ of the total sample are managers, $21.3 \%$ are deputy managers, $33.3 \%$ are head sections, $4 \%$ are marketing managers and $5.3 \%$ are public relations managers, With respect to experience, $14.7 \%$ have less than 5 years experience, $26.7 \%$ of the total sample have an experience between 5 to less than 10 years, $30.7 \%$ of the sample have an experience between 10 to lest hand 15 years, and $28 \%$ of the sample have an experience of 15 years and more.

\begin{tabular}{|c|c|c|c|c|c|}
\hline No. & Question & Mean & S.D & Rank & Level \\
\hline 1 & The company is keen to improve its products & 3.68 & 1.092 & 12 & High \\
\hline 2 & $\begin{array}{c}\text { The company uses new policies in providing the } \\
\text { market it its prod }\end{array}$ & 3.77 & .980 & 9 & High \\
\hline 3 & $\begin{array}{c}\text { The company approves new styles in its operations } \\
\text { management }\end{array}$ & 3.93 & 1.082 & 6 & High \\
\hline 4 & $\begin{array}{c}\text { The company empowers employees to take } \\
\text { decisions related to updating }\end{array}$ & 4.05 & .971 & 4 & High \\
\hline 5 & $\begin{array}{l}\text { The company encourages employees of new } \\
\text { suggestions and thoughts }\end{array}$ & 4.16 & .987 & 3 & High \\
\hline 6 & The company uses new production methods & 3.95 & 1.025 & 5 & High \\
\hline 7 & $\begin{array}{l}\text { The company offers a range of additional } \\
\text { innovative services compared to competitors }\end{array}$ & 4.20 & .870 & 2 & High \\
\hline 8 & $\begin{array}{l}\text { The company is using feedback as a base for } \\
\text { product development }\end{array}$ & 3.92 & 1.088 & 7 & High \\
\hline 9 & $\begin{array}{l}\text { The company has a program to improve and } \\
\text { develop its products. }\end{array}$ & 4.25 & .824 & 1 & High \\
\hline 10 & $\begin{array}{l}\text { The company seeks to innovate new ways to } \\
\text { modify its products. }\end{array}$ & 3.71 & 1.194 & 11 & High \\
\hline 11 & $\begin{array}{l}\text { The company makes changes in its products design } \\
\text { in line with modern technologies. }\end{array}$ & 3.72 & 1.225 & 10 & High \\
\hline 12 & $\begin{array}{l}\text { The company introduces new products from time to } \\
\text { time }\end{array}$ & 3.81 & 1.227 & 8 & High \\
\hline & General Mean & 3.93 & .878 & & High \\
\hline
\end{tabular}

Table (3): shows that means of sample subjects' responses ranged between (3.68-4.25). The results indicate 
high degree of sample's agreement... Table also indicated that statement no. (9) "The company has a program to improve and develop its products." ranked the first with a mean amounting (4.25) which is more than the average mean (3.93)... Statement No. (1) " The company is keen to improve its products "ranked the last with a mean (3.68) which is more the general mean (3.60)

Table (4): Means and standard deviations of sample's responses regarding quality

\begin{tabular}{|c|c|c|c|c|c|}
\hline No. & Question & Mean & S.D & Rank & Level \\
\hline 13 & The company is continuously improving its products quality & 3.96 & 1.309 & 1 & High \\
\hline 14 & $\begin{array}{c}\text { The company focuses on products quality to prevent } \\
\text { competitors entry }\end{array}$ & 3.89 & 1.122 & 3 & High \\
\hline 15 & $\begin{array}{c}\text { The company products are of high quality to meet customers' } \\
\text { needs and desires }\end{array}$ & 3.95 & 1.150 & 2 & High \\
\hline 16 & $\begin{array}{c}\text { The company is keen adopt international quality standards and } \\
\text { specifications }\end{array}$ & 3.60 & 1.103 & 7 & Medium \\
\hline 17 & The company provides complete product based on quality & 3.81 & 1.111 & 4 & High \\
\hline 18 & $\begin{array}{c}\text { The company selects its suppliers according to their products } \\
\text { quality }\end{array}$ & 3.59 & 1.054 & 8 & Medium \\
\hline 19 & Company products are highly reliable & 3.68 & 1.221 & 6 & High \\
\hline 20 & The company follows up customer complaints related to quality & 3.76 & 1.206 & 5 & High \\
\hline & General Mean & 3.78 & 1.038 & & High \\
\hline
\end{tabular}

Table (4) shows means of sample subjects' responses that measure quality ranged between (3.59- 3.96). The results indicate different degrees of sample's agreement from medium to high level. Table also indicated that statement no. (13) "The company is continuously improving its products quality" ranked the first with a mean amounting (3.96) which is more than the average mean (3.78). Statement no. (18) "The company selects its suppliers according to their products quality" ranked the last with a mean (3.59) which is below the general mean (3.78)

Table (5): Means and standard deviations of sample's responses regarding flexibility

\begin{tabular}{|c|c|c|c|c|c|}
\hline No. & Question & Mean & S.D & Rank & Level \\
\hline $\mathbf{2 1}$ & $\begin{array}{c}\text { The company has flexibility to meet different } \\
\text { market specifications }\end{array}$ & 3.36 & 1.181 & 7 & Medium \\
\hline $\mathbf{2 2}$ & $\begin{array}{c}\text { The company has sufficient flexibility to cope } \\
\text { with external stresses }\end{array}$ & 3.73 & 1.070 & 2 & High \\
\hline $\mathbf{2 3}$ & $\begin{array}{c}\text { The company has sufficient flexibility to adapt to } \\
\text { external environmental changes }\end{array}$ & 3.56 & 1.188 & 5 & Medium \\
\hline $\mathbf{2 4}$ & $\begin{array}{c}\text { The company employees have flexibility to } \\
\text { acquire new skills }\end{array}$ & 3.36 & 1.135 & 7 & Medium \\
\hline $\mathbf{2 5}$ & $\begin{array}{c}\text { The company changes its s products to meet } \\
\text { customer requirements }\end{array}$ & 3.15 & 1.087 & 9 & Medium \\
\hline $\mathbf{2 6}$ & $\begin{array}{c}\text { The company uses new techniques in producing } \\
\text { its products }\end{array}$ & 3.38 & 1.077 & 6 & Medium \\
\hline $\mathbf{2 7}$ & $\begin{array}{c}\text { There is a diversity in products to meet } \\
\text { customers' requirements }\end{array}$ & 3.73 & .704 & 2 & High \\
\hline $\mathbf{2 8}$ & $\begin{array}{c}\text { The company seeks to meet all change customers } \\
\text { need }\end{array}$ & 3.79 & .759 & 1 & High \\
\hline $\mathbf{2 9}$ & The company is highly flexible & 3.60 & .973 & 4 & Medium \\
\hline & $\quad \begin{array}{c}\text { General Mean } \\
\text { Tab }\end{array}$ & 3.52 & .733 & & Medium \\
\hline
\end{tabular}

Table (5) shows that means of sample subjects' responses that measure flexibility ranged between (3.15-3.79). The results indicate different degrees of sample's agreement from medium to high level. Table also indicated that statement no. (28) "The company seeks to meet all change customers' needs." ranked the first with a mean (3.79) which is more than the general mean (3.52).Statement no. (25) " The company changes its s products to meet customer requirements" ranked the last with a mean (3.15) which is less than the general mean (3.52) 
Table (6): Means and standard deviations of sample's responses regarding Responsiveness

\begin{tabular}{|c|c|c|c|c|c|}
\hline No. & Question & Mean & S.Deviation & Rank & Level \\
\hline 30 & $\begin{array}{c}\text { The company is able to perform tasks better } \\
\text { than competitors }\end{array}$ & 3.89 & .847 & 1 & High \\
\hline 31 & The company is able to meet its clients' needs & 3.83 & .935 & 3 & High \\
\hline 32 & The company policy is to focus on customer & 3.72 & 1.021 & 8 & High \\
\hline 33 & The company is able to satisfy customers needs & 3.88 & .915 & 2 & High \\
\hline 34 & $\begin{array}{c}\text { The company develops new products with } \\
\text { distinguished features }\end{array}$ & 3.76 & 1.101 & 5 & High \\
\hline 35 & $\begin{array}{c}\text { Company products match with customers } \\
\text { demands }\end{array}$ & 3.76 & 1.149 & 6 & High \\
\hline 36 & $\begin{array}{c}\text { Company responded immediatlyfor customer } \\
\text { needs }\end{array}$ & 3.81 & 1.135 & 4 & High \\
\hline 37 & $\begin{array}{c}\text { There is adversity in company provided } \\
\text { products }\end{array}$ & 3.75 & 1.054 & 7 & High \\
\hline & $\begin{array}{c}\text { General Mean } \\
\text { Tabnh }\end{array}$ \\
\hline
\end{tabular}

Table (6) indicates that means of subjects' responses that measure philanthropic responsibility are ranging from (3.72- 3.89)... Statement no. (30)" The company is able to perform tasks better than competitors "ranked first with a mean (3.89) which is more that the general mean (3.80). Statement no. (32) "The company policy is to focus on customer" ranked the last with a mean (3.72) which is less than the general mean (3.80).

\subsection{Hypothesis Testing}

First Main Hypotheses: There is no statistically significant impact at $(\alpha \leq 05)$ of creativity orientation on achieving competitive advantage (quality, flexibility, responsiveness) at Jordanian pharmaceutical companies.

\section{Table (7): Main Hypothesis Test}

\begin{tabular}{|c|c|c|c|c|c|}
\hline $\mathbf{R}$ & $\mathbf{R}^{2}$ & $\begin{array}{c}\text { T } \\
\text { Calculated }\end{array}$ & $\begin{array}{c}\text { T } \\
\text { Tabulated }\end{array}$ & Sig & Result \\
\hline .699 & .489 & $\mathbf{8 . 3 0 2}$ & 1.99 & $\mathbf{0 . 0 0 0}$ & Reject \\
\hline
\end{tabular}

Table (7) shows that the correlation coefficient was $(\mathrm{R}=.699$ ) which indicate a positive relation between independent variable and dependent variable, in addition $\mathrm{R}^{2}$ was $=.272$ which indicates that $48.9 \%$ of variance in competitive may be interpreted through the variance in creativity orientation. Table also indicates that $t$ calculated value is (8.302) which is more than $\mathrm{t}$ tabulated level $(\mathrm{Sig}=0.000)$. Therefore the null hypothesis is rejected and the alternative one is accepted. So there is statistically significant impact at $(\alpha \leq 05)$ of creativity orientation on achieving competitive advantage (quality, flexibility, responsiveness) at Jordanian pharmaceutical companies

First sub hypothesis

H01.1 There is no statistical significant impact of creativity orientation at level $(\alpha \leq 0.05)$ on quality in pharmaceutical companies in Jordan.

Table (8): First sub Hypothesis Test

\begin{tabular}{|c|c|c|c|c|c|}
\hline $\mathbf{R}$ & $\mathbf{R}^{2}$ & $\begin{array}{c}\mathbf{T} \\
\text { Calculated }\end{array}$ & $\begin{array}{c}\text { T } \\
\text { Tabulated }\end{array}$ & Sig & Result \\
\hline .827 & $\mathbf{. 6 8 9}$ & $\mathbf{1 2 . 5 9 0}$ & $\mathbf{1 . 9 9}$ & $\mathbf{0 . 0 0 0}$ & Reject \\
\hline
\end{tabular}

Table ( 8 ) shows that the correlation coefficient was $(\mathrm{R}=.827$ ) which indicate a positive relation between independent variable and dependent variable, in addition $\mathrm{R}^{2}$ was $=.689$ which indicates that $68.9 \%$ of variance in quality may be interpreted through the variance in creativity orientation. Table also indicates that $t$ calculated value is $(12.690)$ which is more than $\mathrm{t}$ tabulated level $(\mathrm{Sig}=0.000)$. Therefore, the null hypothesis is rejected and the alternative one is accepted. There is statistically significant impact at $(\alpha \leq 05)$ of creativity orientation on quality as a dimension of competitive at Jordanian pharmaceutical companies

\section{Second sub hypothesis}

H01.2 There is no statistical significant impact of creativity orientation at level $(\alpha \leq 0.05)$ on flexibility in pharmaceutical companies in Jordan.

Table (9): Second sub Hypothesis Test

\begin{tabular}{|c|c|c|c|c|c|}
\hline $\mathbf{R}$ & $\mathbf{R}^{2}$ & $\begin{array}{c}\mathbf{T} \\
\text { Calculated }\end{array}$ & $\begin{array}{c}\text { T } \\
\text { Tabulated }\end{array}$ & Sig & Result \\
\hline $\mathbf{0 . 6 0 6}$ & $\mathbf{. 3 6 7}$ & $\mathbf{6 . 5 0 4}$ & $\mathbf{1 . 9 9}$ & $\mathbf{. 0 0 0}$ & Reject \\
\hline
\end{tabular}

Table (9) shows that the correlation coefficient was $(\mathrm{R}=.606)$ which indicate a positive relation between independent variable and dependent variable, in addition $\mathrm{R}^{2}$ was $=.367$ which indicates that $36.7 \%$ of variance in quality may be interpreted through the variance in creativity orientation. Table also indicates that $t$ calculated 
value is $(6.504)$ which is more than $\mathrm{t}$ tabulated level $(\mathrm{Sig}=0.000)$. Therefore the null hypothesis is rejected and the alternative one is accepted. There is statistically significant impact at $(\alpha \leq 05)$ of creativity orientation on flexibility as a dimension of competitive at Jordanian pharmaceutical companies

\section{Third sub hypothesis}

H01.3 There is no statistical significant impact of creativity orientation at level $(\alpha \leq 0.05)$ on responsiveness in pharmaceutical companies in Jordan.

Table (10): Third sub Hypothesis Test

\begin{tabular}{|c|c|c|c|c|c|}
\hline $\mathbf{R}$ & $\mathbf{R}^{2}$ & $\begin{array}{c}\mathbf{T} \\
\text { Calculated }\end{array}$ & $\begin{array}{c}\text { T } \\
\text { Tabulated }\end{array}$ & Sig & Result \\
\hline .282 & .079 & $\mathbf{2 . 5 0 9}$ & $\mathbf{1 . 9 9}$ & $\mathbf{0 . 0 1 4}$ & Reject \\
\hline
\end{tabular}

Table (10) shows that the correlation coefficient was $(\mathrm{R}=.282)$ which indicate a positive relation between independent variable and dependent variable, in addition $\mathrm{R}^{2}$ was $=.079$ which indicates that $7.9 \%$ of variance in responsiveness may be interpreted through the variance in creativity orientation. Table also indicates that $t$ calculated value is (2.509) which is more than $\mathrm{t}$ tabulated level $(\mathrm{Sig}=0.000)$. Therefore the null hypothesis is rejected and the alternative one is accepted. There is statistically significant impact at $(\alpha \leq 05)$ of creativity orientation on responsiveness as a dimension of competitive at Jordanian pharmaceutical companies

\section{Conclusions}

Based on the analysis, the following results were found:

- The results showed that there is a statistically significant impact at $(\alpha \leq 0.05)$ level of creativity orientation on competitive advantage in Jordan Pharmaceutical companies.

- The results showed that there is a statistically significant impact at $(\alpha \leq 0.05)$ level of creativity orientation on quality as a dimension of competitive advantage in Jordan pharmaceutical companies.

- The results showed that there is a statistically significant impact at $(\alpha \leq 0.05)$ level of creativity orientation on flexibility as a dimension of competitive advantage in Jordan pharmaceutical companies.

- The results showed that there is a statistically significant impact at $(\alpha \leq 0.05)$ level of creativity orientation on responsiveness as a dimension of competitive advantage in Jordan pharmaceutical companies.

\section{Recommendations}

1. Pharmaceutical companies should apply for creativity orientation, and all employees in the company should recognize the benefits of creativity orientation in achieving competitive advantage for the company.

2. Pharmaceutical companies should specify their clear objectives in applying creativity orientation

3. Pharmaceutical companies should exert their best efforts provide their employees with full empowerment to apply creativity orientation.

4. Further studies are recommended in other industrial sectors.

\section{References}

Alshibly, H. (2015), "The Effect of Creativity Orientation in Achieving Competitive Advantage for Jordan Telecom Group. Conference Paper. DOI: 10.13140/RG.2.14522.6404.

Askari, M., \& Mortagy, A. K., (2007),"Assessing the Relative Importance of Competitive Priorities in Egyptian Companies". SAM Advanced Management Journal, 72 (3), 35-46.

Berthon, P., Hulbert, J. M., \& Pitt, L. F. (1999). To Serve or Create? Strategic Orientations toward Customers and Innovation. California Management Review, 42(1), 37-58

Dobni, C. (2010),'The relationship between an innovation orientation and competitive strategy. International Journal of Innovation Management, 14(2), 331-357.

Hamel, G. (2006)," The Why, What and How of Management Innovation”. Harvard Business Review, 84(2), 72 84. PMID:16485806

Hasani, K., ,Parviz, K., \& Arman G., (2016),” The Relationship between Innovation Orientation and Strategic Typology in Business Firms". International Journal of Knowledge-Based Organizations, 6 (2),1-20.

Lisboa, A., Skarmeas, D., \& Lages, C. (2011)," Entrepreneurial orientation, exploitative and explorative capabilities, and performance outcomes in export markets: A resource-based approach. Industrial Marketing Management, 40(8), 1274-1284

Sigalas, C. \& Economou, P. (2013), "Developing a measure of competitive advantage", Jjournal of strategy and management, 6 (4): 320-342

Wang, Y., Ning, L., \& Chen, J., (2014).” Product diversification through licensing: empirical evidence from Chinese firms". Eur. Manage. J. 32 (4), 577-586. 